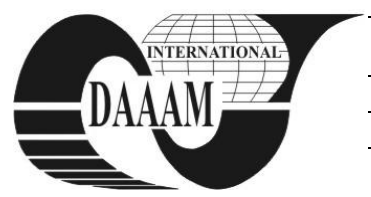

\title{
TEMPERATURE FIELDS SOLVING IN TWO-LAYER PLATE WITH COMSOL MULTIPHYSICS SOFTWARE
}

\author{
JANACOVA, D[agmar]; VASEK, V[ladimir]; MOKREJS, P[avel]; KRENEK, J[iri] \& DRGA, R[udolf]
}

\begin{abstract}
In the paper we deal with study of non-stationary heat conduction problem in a two-layer plane plate. For this purpose we formulate mathematical model describing heating or cooling of a semi-infinite region. The analytical solution of this model we verify by simulation of the mentioned process by use of mathematical software Comsol Multiphysics.

Key words: non-stationary conduction of heat, mathematical model, two-layer plate, Comsol Multiphysics
\end{abstract}

\section{INTRODUCTION}

Most of the technological operations are based on procedures of heat transfer in the materials. These operations are generally energy demanding. Therefore we deal with their optimization (Janáčová et al., 2010), (Vašek \& Dolinay 2010), (Sýkorová et al., 2011), (Šuba et al., 2011). For finding of an appropriate optimization method, it is necessary to get information about given process course. But these data are often hardly experimentally determined and in addition timeconsuming. Therefore mathematical modeling and computer simulation of the studied process can be only alternative how to obtain this information (Carlslaw \& Jaeger, 2008).

In many cases, the mathematical model of given process is very specific and in addition depending on concrete conditions of the process (Janáčová et al., 2007), (Janáčová et al., 2010), (Carlslaw \& Jaeger, 2008). In this paper we will focus on a case of non-stationary conduction of heat in the solid material. We will study problem of non-stationary conduction of heat in the two-layer plate. In the following text we will formulate mathematical model of the mentioned process. Next we will verify validity of the model by comparison of the computed data with computer simulation of the process by use of the mathematical software Comsol Multiphysics.

\section{MATHEMATICAL MODEL DESCRIBING THE SOLVED PROBLEM}

We formulated mathematical model during heating or cooling of two-layer semi-infinite plate in the region $0<b<\infty$. The plate of the initial constant temperature $t_{p}$ was exposed to the sudden one-sided heat action. Geometrical sketch of the problem you can see in Fig. 1.

In accordance with literature (Carlslaw \& Jaeger, 2008), we described mathematical model of the process by Fourier equation of the heat conduction (1) with initial and boundary conditions (2) - (7):

$$
\begin{gathered}
\frac{\partial t_{1}}{\partial \tau}(x, \tau)=a_{1} \frac{\partial^{2} t_{1}}{\partial x^{2}}(x, \tau), \tau>0,0<x<b \\
\frac{\partial t_{2}}{\partial \tau}(x, \tau)=a_{2} \frac{\partial^{2} t_{2}}{\partial x^{2}}(x, \tau), \tau>0, b<x<\infty \\
t_{1}(x, 0)=t_{2}(x, 0)=t_{p} \\
t_{1}(0, \tau)=t_{o}
\end{gathered}
$$

$$
\begin{gathered}
\frac{\partial t_{2}(\infty, \tau)}{\partial x}=0 \\
t_{1}(b, \tau)=t_{2}(b, \tau) \\
\lambda_{1} \frac{\partial t_{1}(b, \tau)}{\partial \tau}=\lambda_{2} \frac{\partial t_{2}(b, \tau)}{\partial \tau}
\end{gathered}
$$

where $a_{1}=\frac{\lambda_{1}}{\rho_{1} \cdot c_{p 1}}$ or $a_{2}=\frac{\lambda_{2}}{\rho_{2} \cdot c_{p 2}}$ are thermal conductivity of first or second layer of the heated (cooled) solid.

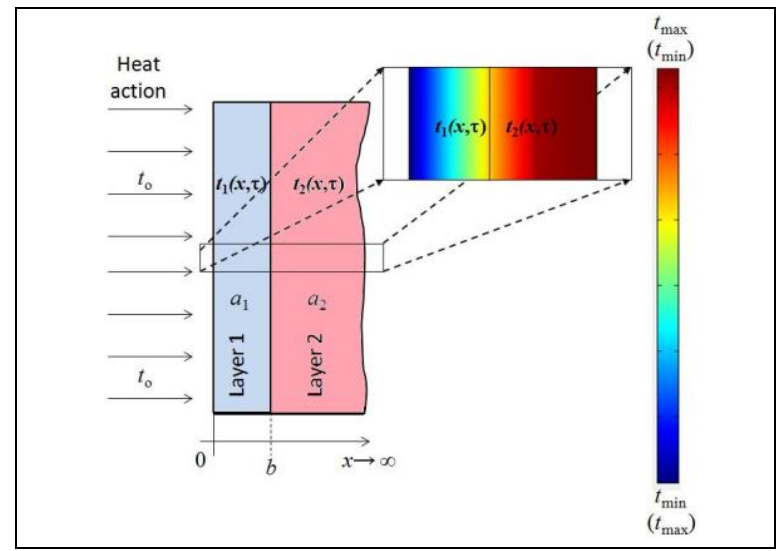

Fig. 1. Model of non-stationary heat conduction in two-layer plate

The condition (3) is assumption of the initial constant temperature in the plate. The boundary condition (4) is assumption of the time independent temperature in the boundary of first layer and surrounding fluid. The boundary condition (5) is assumption of semi-infinite region. The boundary conditions (6) and (7) are assumptions of perfect contact of the layers. The relation (8) and (9) describe analytical solutions of the model.

The equation (8) describes temperature fields in the first layer $t_{1}(x, \tau)$ (Carlslaw \& Jaeger, 2008):

$\frac{t_{1}-t_{p}}{t_{o}-t_{p}}=\left[\sum_{n=0}^{\infty} h^{n}\left\{\operatorname{erfc} \frac{(2 n+1) b+x}{2 \sqrt{a_{1} \tau}}-h \cdot \operatorname{erfc} \frac{(2 n+1) b-x}{2 \sqrt{a_{1} \tau}}\right\}\right]$

Distribution of temperature in the second layer $t_{2}(x, \tau)$ can be described by equation (9) (Carlslaw \& Jaeger, 2008):

$\frac{t_{2}-t_{p}}{t_{o}-t_{p}}=\frac{2 K_{\varepsilon}}{1+K_{\varepsilon}} \sum_{n=1}^{\infty} h^{n-1} \operatorname{erfc}\left(\frac{x-b+(2 n-1) K_{a}^{-\frac{1}{2}} b}{2 \sqrt{a_{2} \tau}}\right)$

where

$$
\begin{gathered}
h=\frac{1-K_{\varepsilon}}{1+K_{\varepsilon}} \\
K_{a}^{-\frac{1}{2}}=\sqrt{\frac{a_{2}}{a_{1}}}=\sqrt{\frac{\lambda_{2} \rho_{1} c_{p 1}}{\lambda_{1} \rho_{2} c_{p 2}}}
\end{gathered}
$$




$$
K_{\varepsilon}=\frac{\lambda_{1}}{\lambda_{2}} \sqrt{\frac{\lambda_{2} \rho_{1} c_{p 1}}{\lambda_{1} \rho_{2} c_{p 2}}}
$$

where the symbols mean:

$a$-thermal diffusivity, $\mathrm{m}^{2} \cdot \mathrm{s}^{-1}$;

$c_{p}$-specific thermal capacity, $\mathrm{J} \cdot \mathrm{kg}^{-1} \cdot \mathrm{K}^{-1}$;

$t \quad$-temperature of the heated (cooled) body, ${ }^{\circ} \mathrm{C}$;

$t_{o} \quad$ - ambient temperature, ${ }^{\circ} \mathrm{C}$;

$t_{p} \quad$-initial temperature of the heated (cooled) body, ${ }^{\circ} \mathrm{C}$;

$x \quad$-space coordinate, $\mathrm{m}$;

-thickness, m;

-thermal conductivity, $\mathrm{W} \cdot \mathrm{m}^{-1} \cdot \mathrm{K}^{-1}$;

-density, $\mathrm{kg} \cdot \mathrm{m}^{-3}$;

-time, s;

-properties of first layer;

-properties of second layer.

\section{COMPUTER MODELING OF THE PROCESS}

We calculated temperature fields by use of software Comsol Multiphysics. In the fig. $2-4$ we show temperature fields that we simulated by under the following conditions:

$\begin{array}{ll}\text { Initial temperature of the plate: } & 130{ }^{\circ} \mathrm{C} \\ \text { Ambient temperature: } & 18{ }^{\circ} \mathrm{C} \\ \text { Thickness of first layer: } & 25 \mathrm{~mm} \\ \text { Thickness of second layer: } & 20 \mathrm{~mm} \\ \text { Thermal diffusivity of first layer : } & 1.5 \cdot 10^{-6} \mathrm{~m}^{2} \cdot \mathrm{s}^{-1} \\ \text { Thermal diffusivity of second layer: } & 5.2 \cdot 10^{-6} \mathrm{~m}^{2} \cdot \mathrm{s}^{-1}\end{array}$

The obtained results were in accordance with data that we computed according to analytical solutions (8) and (9) with mathematical software Maple.

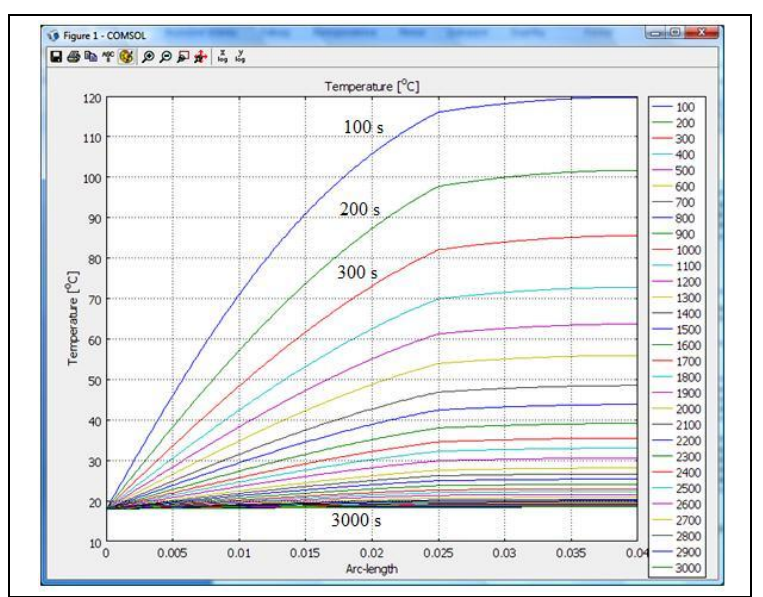

Fig. 2. Temperature fields in the plate

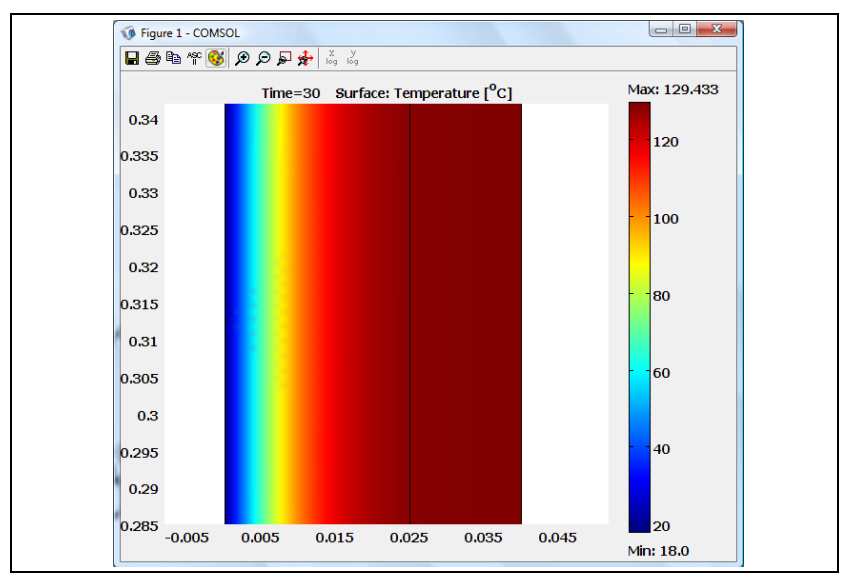

Fig. 3. Distribution of temperature in time 10 seconds

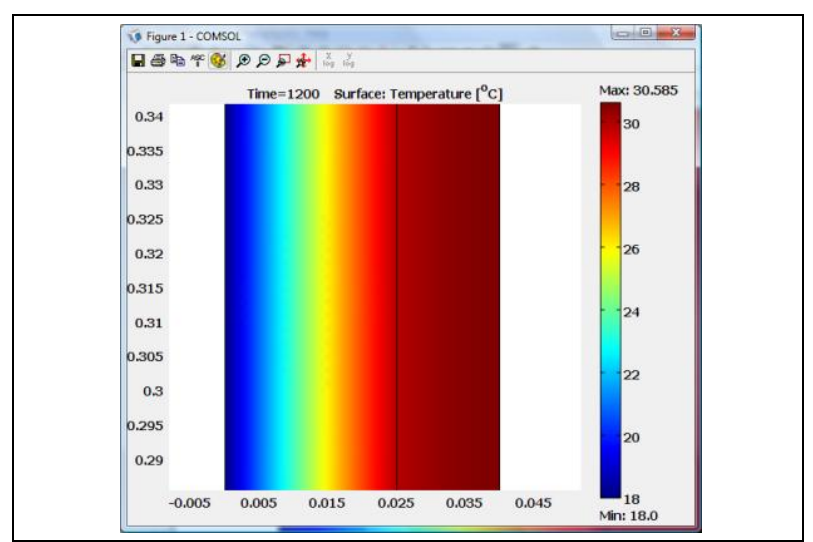

Fig. 4. Distribution of temperature in time 1200 seconds

\section{CONCLUSION}

We formulated mathematical model that is suitable for description of heating or cooling of two-layer plane plate in the case of the semi-infinite region.

Validity of the formulated model we verified by comparison of the data that we computed according to analytical solutions (8) and (9) with computer simulation of the process by use of Comsol Multiphysics. The obtained results proved possibility to use our formulated model and its analytical solution for description of the real technological processes.

The computed data enabled us also determine main parameters that influence heating or cooling process course and compute economical costs of the studied process.

\section{ACKNOWLEDGEMENTS}

This work was supported by the Ministry of Education, Youth and Sports of the Czech Republic under the Research Plan No. MSM 7088352102 and by the European Regional Development Fund under the project CEBIA-Tech No. CZ.1.05/2.1.00/03.0089.

\section{REFERENCES}

Carslaw, H. S. \& Jaeger, J. C. (2008). Conduction of Heat in Solids, Clarendon Press, Oxford

Janáčová, D.; Charvátová, H.; Šuba, O.; Kolomazník, K.; Vašek, V. (2009). Treatment of Electronic Waste", Proceedings of International Carpathian Control Conference 2009, Zakopané, Poland.

Janáčová, D. et al. (2010). Modeling of non-stationary heat field in a plane plate for asymmetric problem, Proceedings of the14th WSEAS International Conference on Systems. Latest Trands on Systems.Volume II, August 25 - 27, 2007, WSEAS Press (GR), Rhodes

Sýkorová, L.; Suba, O.; Malachová, M.; Černý, J. (2011) Temperature Field Simulation of Polymeric Materials During Laser Machining Using COSMOS / M Softwar , Proceedings of 13th WSEAS International Conference on Automatic control, modelling \& simulation (ACMOS'11), WSEAS Press, Lanzarote, Canary Islands

Šuba, O.; Sýkorová, L.; Šanda, Š.; Staněk, M. (2011). Modelling of Thermal Stresses in Printed Circuit Boards, Proceedings of the 13th WSEAS International Conference on Automatic control, modelling \& simulation (ACMOS'11), WSEAS Press, Lanzarote, Canary Islands

Vašek, L. \& Dolinay, V. (2010). Simulation Model of Heat Distribution and Consumption in Municipal Heating Network, Proceedings of 14th WSEAS International Conference on Systems. Latest Trends on Systems. Volume II, p.439-442, WSEAS Press (GR), Rhodes 